\title{
Estrutura de Capital e Governança Corporativa nas Empresas Listadas na BM\&FBovespa
}

\section{Resumo}

Objetivo: analisar a relação entre estrutura de capital e governança corporativa.

Método: a amostra reúne as empresas listadas na BM\&FBOVESPA no período de 2010 a 2014. Os dados foram coletados no website do BNDES e na base Economática ${ }^{\circledast}$ e a análise quantitativa foi realizada por meio de teste de diferenças entre médias, análise de correlação e regressão linear múltipla. Resultados: as empresas não participantes dos níveis diferenciados de governança corporativa apresentam maior endividamento médio. No ano de 2012, as empresas receberam maior volume de recursos financiados pelo BNDES, destacandose a empresa Petrobras. Os resultados apontam que a governança corporativa influenciou negativamente o endividamento subsidiado, e que a rentabilidade apresentou uma relação negativa com todos os quatro tipos de endividamento analisados, confirmando-se no mercado brasileiro o que preceitua a Teoria Pecking Order.

Contribuições: A pesquisa contribui para enriquecer a bibliografia sobre estrutura de capital, ao incorporar a dívida subsidiada como uma das variáveis explicativas do modelo. Devido à sua grande importância para o meio empresarial, e ao fato de os resultados dos estudos acadêmicos serem, em linhas gerais, heterogêneos, as discussões sobre estrutura de capital contribuem de alguma forma para o avanço nesse campo de pesquisa.

Palavras-chave: Estrutura de capital. Governança corporativa. Endividamento subsidiado.
Bruno Goes Pinheiro

Mestrado em Administração e Controladoria pela Universidade Federal do Ceará (UFC) e Analista bancário no Banco do Nordeste do Brasil (BNB). Contato: Avenida Dr. Silas Munguba, 5700. Ambiente de Crédito Comercial e Cartões. Passaré. Fortaleza(CE). CEP: 60743-902. E-mail: brunogoesp@gmail.com

\section{Alessandra Carvalho de Vasconcelos \\ Doutorado em Engenharia de Produção pela Universidade Federal de Santa Catarina (UFSC) e Professora na Universidade Federal do Ceará (UFC). Contato: Av. da Universidade, 2431. Departamento de Contabilidade. Benfica. Fortaleza (CE). CEP: 60020-180. \\ E-mail: alevasconcelos.ufc@gmail.com}

Márcia Martins Mendes De Luca Doutorado Controladoria e Contabilidade pela Universidade de São Paulo (USP) e Professora na Universidade Federal do Ceará (UFC). Contato: Av. da Universidade, 2431. Departamento de Contabilidade. Benfica. Fortaleza (CE). CEP: 60020-180. E-mail: marciammdeluca@gmail.com

\section{Vicente Lima Crisóstomo}

Doutorado em Nuevas Tendencias En Dirección de Empresas pela Universidad de Valladolid e Professor na Universidade Federal do Ceará (UFC). Contato: Av. da Universidade, 2431. Departamento de Contabilidade. Benfica. Fortaleza (CE). CEP: 60020-180.

E-mail: vicentelc@gmail.com 


\section{Introdução}

A estrutura de capital constitui um dos principais itens das finanças corporativas (Correa, Basso \& Nakamura, 2013; David, Nakamura \& Bastos, 2009; Terra, 2009). O tema está relacionado à utilização do capital próprio e do capital de terceiros para financiar projetos. O capital próprio é representado pelos recursos oriundos da retenção de lucros e também dos recursos investidos pelos acionistas da empresa, recursos esses que não têm prazo de reembolso. Já o capital de terceiros corresponde aos recursos obtidos por meio da contração de dívidas, em que há um prazo determinado para quitação, além de pagamento de juros pelo seu uso (Assaf Neto \& Lima, 2010).

O tema começou a ser mais discutido por Modigliani e Miller (1958), segundo os quais a forma de financiamento de uma empresa é irrelevante para determinar o seu valor. Diversos estudos foram realizados, e algumas teorias foram elaboradas, na tentativa de se determinarem os principais fatores que influenciam a utilização de capital próprio ou de terceiros e se a forma como são utilizados afeta o valor da empresa (Bastos, Nakamura \& Basso, 2009; Handoo \& Sharma, 2014; Jõeveer, 2013; Thippayana, 2014).

A teoria Trade-off e a teoria Pecking Order são as duas mais utilizadas em estudos empíricos e dominam a discussão sobre estrutura de capital. Contudo, não há consenso sobre qual delas explica melhor a estrutura de capital e seus determinantes (Campos \& Nakamura, 2013; Correa et al., 2013; Pohlmann \& Iudícibus, 2010). A teoria da Agência e a teoria Market Timing também estão presentes em estudos empíricos sobre estrutura de capital, e seus pressupostos já encontraram resultados que mostram a sua importância no contexto das teorias sobre estrutura de capital (Baker \& Wurgler, 2002; Chen, Chen, Chen \& Huang, 2013; Sun, Ding, Guo, \& Li, 2016; Yang, 2013).

Crisóstomo e López-Iturriaga (2011) sugerem que inúmeros fatores de diferentes naturezas podem influenciar a forma como as empresas conseguem obter os recursos no mercado, dentre eles, destaca-se a governança corporativa, pois as empresas que adotam as melhores práticas detêm mais vantagens para contrair endividamento (Silveira, Perobelli, \& Barros; 2008). Mesmo que a governança corporativa já tenha sido testada como possível determinante da estrutura de capital (Chang, Chen, Chou \& Huang, 2015; Chang, Chou \& Huang, 2014; Silveira et al., 2008; Vieira, Velasquez, Losekann \& Ceretta, 2011), os resultados são contraditórios.

Diante do exposto, o presente estudo procura uma resposta para o seguinte questionamento: Qual a relação entre estrutura de capital e governança corporativa?

O estudo tem como objetivo geral analisar a relação entre estrutura de capital e governança corporativa e, ainda, os seguintes objetivos específicos: (i) identificar o perfil das dívidas subsidiadas nas empresas que adotam as melhores práticas de governança e o das dívidas das demais empresas; (ii) identificar a diferença entre o endividamento nas empresas que adotam as melhores práticas de governança $\mathrm{e}$ o endividamento nas demais; e (iii) investigar a relação entre endividamento e os fatores apontados pela literatura como determinantes da estrutura de capital.

A amostra reúne as empresas listadas na BM\&FBOVESPA no período de 2010 a 2014 . Os dados foram coletados no Banco Nacional de Desenvolvimento Econômico e Social [BNDES] (2016), no tocante ao endividamento subsidiado; e na base Economática ${ }^{\oplus}$, no que tange à situação econômico-financeira. A análise quantitativa foi realizada por meio de métodos como teste de diferenças entre médias, análise de correlação e regressão linear múltipla.

Como as teorias sobre estrutura de capital foram elaboradas em economias desenvolvidas, torna-se oportuna a sua validação em mercados de países em desenvolvimento, como o Brasil (Brito, Corrar, \& Batistella, 2007). Apesar de haver inúmeros estudos teóricos e práticos sobre o tema, a questão ainda não está definida, e as imperfeições dos mercados emergentes requerem ajustes nos modelos já aplicados (Assaf Neto \& Lima, 2010). 
Além disso, a contribuição principal deste estudo reside na análise da estrutura de capital, em especial, da composição do endividamento, sob o enfoque da governança corporativa, ao incorporar a participação da empresa em um dos níveis diferenciados (Nível 1, Nível 2 e Novo Mercado) como fator capaz de explicar o endividamento nas companhias listadas na BM\&FBOVESPA. Além disso, este estudo não tratará o capital de terceiros de forma homogênea (Póvoa \& Nakamura, 2015), pois considera as dívidas contraídas no BNDES (2016) uma das medidas de endividamento, o que o diferencia dos demais. $\mathrm{O}$ BNDES foi selecionado intencionalmente, por ser o banco de desenvolvimento mais atuante na concessão de crédito no Brasil (Bachiller, 2016; Póvoa, Vieira, Kudlawicz \& Bach, 2015).

\section{Referencial Teórico}

\subsection{Teorias sobre estrutura de capital}

Ao longo dos últimos 50 anos, diferentes teorias procuraram explicar a forma como as empresas determinam sua estrutura de capital. Considerando um mercado de capitais perfeito, Modigliani e Miller (1958) propuseram que a estrutura de capital é irrelevante para a determinação do valor da empresa. Entretanto, a partir das suas propostas, outros estudos encontraram resultados que mostram a não irrelevância da estrutura de capital, devido à influência de variados fatores. Esse avanço na pesquisa indica que, de fato, há imperfeições no mercado que ocasionam a não irrelevância da estrutura de capital, como impostos, custos de agência, custos de falência e assimetria informacional. Essas imperfeições são abordadas sob distintos enfoques, pelas teorias Trade-off, Pecking Order, da Agência e Market Timing.

A teoria Trade-off propõe que existe uma estrutura ótima de capital, obtida pela combinação de capital próprio e capital de terceiros. De acordo com essa teoria, a estrutura de capital ótima é aquela que maximiza a possibilidade de uso de endividamento externo para financiar investimentos (Myers, 1984).

Segundo a teoria Pecking Order, de Myers (1984) e Myers e Majluf (1984), há uma hierarquia (ou ordem de preferência) ideal a ser adotada na escolha das fontes de financiamento. A primeira forma de se financiar seria a utilização de recursos internos, por meio da retenção de lucros. Caso esses recursos não sejam suficientes, a empresa daria então preferência ao financiamento externo, por meio da contração de dívida. E, em último caso, proceder-se-ia a uma emissão de ações, com reflexo no valor da ação, na divisão de dividendos e, consequentemente, na estrutura de propriedade, o que não é bem aceito pelos acionistas principais.

A teoria da Agência, por seu turno, analisa a relação entre o agente e o principal, assim como os custos respectivos. A relação de agência pode ser caracterizada como um contrato, no qual uma ou mais pessoas (principal) delegam uma terceira (agente) para executar serviços (Jensen \& Meckling, 1976). O problema de agência surge quando ambas as partes dessa relação forem maximizadoras de sua utilidade, podendo, para isso, o agente agir em benefício próprio (Jensen \& Meckling, 1976). No intuito de diminuir esses conflitos, o principal incorre em custos de agência, que são aqueles gastos realizados no intuito de verificar se o agente o prejudicou (Jensen \& Meckling, 1976). Jensen (1986) admite que a dívida tem capacidade/potencial para reduzir os custos de agência, pois, por meio dela há um menor fluxo de caixa livre, reduzindo os gastos a critério do agente, que, dispondo de poucos recursos livres, deverá utilizá-los da forma que julgar mais racional.

Por sua vez, a teoria Market Timing, formulada por Baker e Wurgler (2002), refere-se à prática oportunística de emissão de ações quando a empresa vivencia um valor de mercado favorável e de recompra de ações a preços baixos. A prática tem como objetivo explorar flutuações temporárias no custo de capital próprio, em comparação com o custo de outras formas de captação. 


\subsection{Estrutura de capital e governança corporativa}

A adoção de boas práticas de governança corporativa visa reduzir os problemas de agência decorrentes da relação entre acionistas e gestores. Assim, as empresas com mais qualidade de governança sofrem menos conflitos de agência (Chang et al., 2014; Chang et al., 2015, Jiraporn, Kim, Kim \& Kitsabunnarat, 2012).

As boas práticas de governança são vistas como capazes de melhorar a gestão da empresa, o seu desempenho organizacional, de incrementar seu valor de mercado e reduzir a assimetria informacional por meio de um processo de divulgação mais aprimorado (Armstrong, Guay, \& Weber, 2010; Detthamrong, Chancharat \& Vithessonthi, 2017). Este conjunto de benefícios tende a melhorar a relação da empresa com o mercado de crédito externo (Chen, Chung, Hsu, \& Wu, 2010). Nesse sentido, a alta qualidade da governança corporativa pode contribuir para melhorar o acesso a recursos externos, qualquer que seja $o$ ambiente institucional (Silveira et al., 2008; Vieira et al., 2011).

Estudos empíricos em contextos internacionais evidenciam que a melhor qualidade do sistema de governança corporativa contribui positivamente para o acesso ao endividamento, seja em países desenvolvidos (Liao, Mukherjee \& Wang, 2015) seja em países de mercados emergentes (Detthamrong et al., 2017).

No Brasil, estudos também concluíram que boas práticas de governança corporativa contribuem para o acesso ao financiamento por meio de dívida (Fonseca, Silveira \& Hiratuka, 2016; Silveira et al., 2008), sugerindo que esse resultado deve-se à redução da assimetria informacional e também à dificuldade de captação por meio da emissão de ações, como comentado por Silveira et al. (2008), ao considerar que o valor da ação da empresa pode não incorporar a qualidade da governança corporativa uma vez que investidores têm dificuldade de avaliar precisamente esta qualidade. Depreende-se que a adoção de boas práticas de governança corporativa seja capaz de facilitar o acesso ao endividamento da empresa brasileira.

\subsection{Estudos empíricos anteriores}

Jiraporn et al. (2012) analisaram a relação entre a qualidade da governança e a alavancagem de empresas listadas no Institutional Shareholder Services (ISS) no período de 2001 a 2004. Os autores utilizaram dois índices de governança corporativa, sendo um deles com base em categorias adotadas em estudos anteriores; enquanto o outro foi construído com base nas recomendações do ISS. Como principal resultado, encontrou-se uma relação negativa e significante entre os dois índices e a alavancagem, ressaltando-se que cada índice foi testado em um modelo de regressão específico. Portanto, os resultados confirmam a hipótese de influência entre as variáveis, porém de forma negativa, ou seja, há uma relação inversa entre a qualidade da governança e a alavancagem.

Ao analisar 154 empresas não financeiras com ações negociadas na BM\&FBOVESPA, Silveira et al. (2008), identificaram alguns fatores que influenciam a alavancagem, a saber: qualidade da governança corporativa (relação positiva), rentabilidade, crescimento e volatilidade (relação negativa). Os autores separaram o índice de governança em duas dimensões (transparência, e estrutura de propriedade e conselho de administração). Constataram que o índice de transparência não influencia o grau de alavancagem, enquanto o índice de estrutura de propriedade e conselho de administração o influencia positivamente. Os autores constataram a importância da governança corporativa como um dos determinantes da estrutura de capital. 
Em outro estudo que correlaciona as temáticas, Vieira et al. (2011) procuraram identificar a influência da governança na estrutura de capital e no desempenho nas empresas participantes dos níveis diferenciados de governança da BM\&FBOVESPA. Os autores analisaram as 84 empresas listadas no Nível 1, no Nível 2 e no Novo Mercado no período de 2001 a 2006, e o índice de governança utilizado no estudo corresponde à soma de 23 variáveis dummy. Observou-se que a independência do conselho de administração apresentou significância negativa, enquanto a variação na concentração de ações nas mãos dos cinco maiores acionistas e a variação na liquidez em bolsa são positivamente significantes. Segundo ressaltam os autores, as empresas que aderiram ao Nível 1, as que aderiram ao Nível 2 e aquelas que optaram pelo Novo Mercado vêm adotando as melhores práticas de governança sugeridas pela BM\&FBOVESPA, mas o índice de governança do estudo não influenciou o seu endividamento.

Fonseca et al. (2016) avaliaram a influência da governança corporativa no montante e no perfil do endividamento em 252 empresas brasileiras de capital aberto no período de 2000 a 2013. A variável governança corporativa foi mensurada por uma dummy que assumiu o valor igual à unidade, a partir do ano em que a empresa aderiu a um dos três segmentos de listagem, e valor nulo nos demais anos. Verificou-se que o endividamento no período t- 1 é positivamente correlacionado com o endividamento atual, e que há uma relação negativa da rentabilidade e das oportunidades de crescimento com o endividamento. Constatou-se, ainda, que a estrutura dos ativos e a volatilidade dos fluxos de caixa influenciam negativamente o endividamento de curto prazo, e que há uma relação positiva entre o tamanho e o endividamento total. No tocante à governança corporativa, os autores observaram uma relação positiva com o endividamento total, oneroso e de longo prazo, constatando-se que a governança facilita o acesso ao financiamento com capital de terceiros, mas a variável governança corporativa apresentou uma relação negativa com o endividamento de curto prazo.

Diante do exposto, reforça-se a relevância desta pesquisa para o aprofundamento da análise da estrutura de capital sob o enfoque da governança, ao incorporar a participação nos níveis diferenciados da BM\&FBOVESPA como fator capaz de explicar a estrutura de capital nas companhias abertas listadas naquela instituição. Ressalta-se que este estudo se diferencia dos demais, porque não considera o capital de terceiros de forma homogênea, pois compreende a análise das dívidas subsidiadas das empresas junto ao BNDES (2016) como uma das medidas de endividamento.

\section{Procedimentos Metodológicos}

Quanto aos propósitos, a pesquisa classifica-se como descritiva, pois identifica a situação do evento e estabelece como as variáveis estão relacionadas entre si (Gray, 2012). No tocante aos procedimentos, trata-se de pesquisa uma documental. A fonte dos documentos é a secundária (Cooper \& Schindler, 2011), pois consultaram-se os financiamentos obtidos pelas empresas no website do BNDES (2016); os dados sobre o segmento de listagem de cada empresa foram coletados junto ao website da BM\&FBOVESPA; e os dados econômico-financeiros dos exercícios sociais entre 2010 e 2014, foram consultados na base da Economática ${ }^{\circledast}$. Quanto à abordagem, a pesquisa classifica-se como quantitativa, haja vista que os dados são organizados, tabulados e submetidos aos testes estatísticos (Martins \& Theóphilo, 2009).

A população do estudo reúne as companhias de capital aberto listadas na BM\&FBOVESPA no período de 2010 a 2014. Devido ao fato de as demonstrações contábeis das empresas do setor financeiro (bancos, companhias de seguros e de investimentos) apresentarem uma estrutura diferente em comparação com as empresas não financeiras, que se inclusos no estudo podem distorcer os resultados, aquelas foram excluídas da amostra.

A Figura 1 evidencia alguns detalhes operacionais e as bases teóricas das variáveis utilizadas no estudo. 


\begin{tabular}{|c|c|c|c|c|}
\hline Variável & Descrição & Fonte & $\begin{array}{c}\text { Fundamentação } \\
\text { teórica }\end{array}$ & $\begin{array}{l}\text { Relação } \\
\text { esperada }\end{array}$ \\
\hline $\begin{array}{l}\text { Endividamento de Curto } \\
\text { Prazo (ENDCP) }\end{array}$ & $\begin{array}{l}\text { (Dívida de Curto Prazo + } \\
\text { Debêntures de Curto Prazo) / Ativo }\end{array}$ & Economática ${ }^{\circledR}$ & $\begin{array}{l}\text { Crisóstomo e Pinheiro } \\
\text { (2015) }\end{array}$ & \\
\hline $\begin{array}{l}\text { Endividamento de Longo } \\
\text { Prazo (ENDLP) }\end{array}$ & $\begin{array}{l}\text { (Dívida de Longo Prazo + } \\
\text { Debêntures de Longo Prazo) / Ativo }\end{array}$ & Economática ${ }^{\circledR}$ & $\begin{array}{l}\text { Crisóstomo e Pinheiro } \\
(2015)\end{array}$ & \\
\hline $\begin{array}{l}\text { Endividamento Total } \\
\text { (ENDTOT) }\end{array}$ & $\begin{array}{l}\text { (Dívida de Curto Prazo + Dívida } \\
\text { de Longo Prazo + Debêntures de } \\
\text { Curto Prazo + Debêntures de Longo } \\
\text { Prazo) / Ativo }\end{array}$ & Economática ${ }^{\circledR}$ & $\begin{array}{l}\text { Crisóstomo e Pinheiro } \\
(2015) \\
\text { Silveira et al. (2008) }\end{array}$ & \\
\hline $\begin{array}{l}\text { Endividamento } \\
\text { Subsidiado (ENDSUB) }\end{array}$ & $\begin{array}{l}\text { Dívida subsidiada junto ao BNDES } \\
\text { / Ativo }\end{array}$ & $\begin{array}{l}\text { BNDES (2016) } \\
\text { Economática } \mathbb{} \text { ) }\end{array}$ & $\begin{array}{l}\text { Póvoa e Nakamura } \\
(2015)\end{array}$ & \\
\hline $\begin{array}{l}\text { Governança Corporativa } \\
\text { (GC) }\end{array}$ & $\begin{array}{l}\text { GC = } 1 \text {, se listada em um dos níveis } \\
\text { diferenciados de governança; GC = } \\
0, \text { no caso negativo }\end{array}$ & BM\&FBovespa & Fonseca et al. (2016) & Positiva \\
\hline Rentabilidade (ROA) & Lucro Líquido / Ativo & Economática® & $\begin{array}{l}\text { De Luca, Maia, } \\
\text { Cardoso, Vasconcelos } \\
\text { e Cunha (2014) }\end{array}$ & Negativa \\
\hline Tamanho (TAM) & Logaritmo Natural do Ativo & Economática ${ }^{\circledR}$ & $\begin{array}{l}\text { Machado, Prado, } \\
\text { Vieira, Antonialli e } \\
\text { Santos (2015) } \\
\text { Chang et al. (2014) }\end{array}$ & Positiva \\
\hline Tangibilidade (TANG) & Imobilizado / Ativo & Economática ${ }^{\circledR}$ & Chang et al. (2014) & Positiva \\
\hline
\end{tabular}

Figura 1. Variáveis da pesquisa

Fonte: elaborada pelos autores.

Cabe destacar que a governança corporativa é caracterizada neste artigo como uma variável dum$m y$, na qual as empresas listadas nos níveis diferenciados de governança corporativa da BM\&FBOVESPA (Nível 1, Nível 2 e Novo Mercado) assumem valor igual à unidade, enquanto as demais empresas assumem o valor nulo. Procedimento semelhante é adotado em estudos que mensuram a governança corporativa (Arruda, Girão \& Lucena, 2015; Barros, Silva \& Voese, 2015; Dalmácio, Lopes, Rezende \& Sarlo Neto, 2013; Fonseca et al., 2016). Destarte, a participação nos segmentos diferenciados representa a adoção de melhores práticas de governança corporativa.

A variável governança corporativa levou em consideração a data em que a companhia aderiu ao referido nível. Por exemplo, se uma empresa estava listada no Mercado Tradicional até 2012 e depois passou para o Novo Mercado em 2013, foi atribuído 0 para essa empresa nos anos de 2010 a 2012, e entre 2013 e 2014 foi atribuído 1 por esta fazer parte de um dos níveis diferenciados de governança corporativa.

A Bolsa de Valores de São Paulo (Bovespa), em 2000, criou os níveis diferenciados de governança corporativa que classificam as empresas comprometidas com as melhores práticas do mercado. Por ordem crescente de exigência de adoção de boas práticas, têm-se os seguintes níveis: Nível 1 (N1), Nível 2 (N2) e Novo Mercado (NM). As empresas listadas na BM\&FBOVESPA, em caráter voluntário de adesão, caso cumpram as regras estabelecidas podem ser listadas nos segmentos. Resumidamente, para participar dos níveis 1 e 2 as empresas devem diminuir a concentração acionária. O novo mercado constitui-se no nível diferenciado com as regras mais rígidas de governança corporativa, como, por exemplo, as empresas devem ter seu capital social exclusivamente em ações ordinárias, ou seja, ações com direito a voto.

No modelo estatístico da pesquisa, como existem quatro tipos de endividamento - de curto prazo (ENDCP), de longo prazo (ENDLP), total (ENDTOT) e subsidiado (variáveis dependentes) -, têm-se quatro regressões. Os modelos matemáticos utilizados são definidos nas equações 1, 2, 3 e 4. 


$$
\begin{aligned}
& \mathrm{ENDCP}_{\mathrm{i}^{\prime} \mathrm{t}}=\alpha+\beta 1 \mathrm{GC}_{\mathrm{i}^{\prime} \mathrm{t}}+\beta 2 \mathrm{ROA}_{\mathrm{i}^{\prime} \mathrm{t}}+\beta 3 \mathrm{TAM}_{\mathrm{i}^{\prime} \mathrm{t}}+\beta 4 \mathrm{TANG}_{\mathrm{i}^{\prime} \mathrm{t}}+\varepsilon \\
& \operatorname{ENDLP}_{\mathrm{i}^{\prime} \mathrm{t}}=\alpha+\beta 1 \mathrm{GC}_{\mathrm{i}^{\prime} \mathrm{t}}+\beta 2 \mathrm{ROA}_{\mathrm{i}^{\prime} \mathrm{t}}+\beta 3 \mathrm{TAM}_{\mathrm{i}^{\prime} \mathrm{t}}+\beta 4 \mathrm{TANG}_{\mathrm{i}^{\prime} \mathrm{t}}+\varepsilon \\
& \text { ENDTOT }_{\mathrm{i}^{\prime} \mathrm{t}}=\alpha+\beta 1 \mathrm{GC}_{\mathrm{i}^{\prime} \mathrm{t}}+\beta 2 \mathrm{ROA}_{\mathrm{i}^{\prime} \mathrm{t}}+\beta 3 \mathrm{TAM}_{\mathrm{i}^{\prime} \mathrm{t}}+\beta 4 \mathrm{TANG}_{\mathrm{i}^{\prime} \mathrm{t}}+\varepsilon \\
& \text { ENDSUB }_{\mathrm{i}^{\prime} \mathrm{t}}=\alpha+\beta 1 \mathrm{GC}_{\mathrm{i}^{\prime} \mathrm{t}}+\beta 2 \mathrm{ROA}_{\mathrm{i}^{\prime} \mathrm{t}}+\beta 3 \mathrm{TAM}_{\mathrm{i}^{\prime} \mathrm{t}}+\beta 4 \mathrm{TANG}_{\mathrm{i}^{\prime} \mathrm{t}}+\varepsilon
\end{aligned}
$$

Em que, $E N D_{i^{\prime} t}$ é o endividamento da empresa $i$ no ano $t$, conforme a sua natureza (curto prazo, longo prazo, total ou subsidiado); $\alpha$ é o intercepto da reta; $\beta$ são os coeficientes angulares; $G C_{i^{\prime} t}$ (governança corporativa), $R O A_{i^{\prime} t}$ (rentabilidade), $T A M_{i^{\prime} t}$ (tamanho) e $T A N G_{i^{\prime} t}$ (tangibilidade) são as variáveis independentes da empresa $i$ no ano $t$; e $\varepsilon$ é o termo de erro.

Além dessas variáveis, foram também utilizadas as variáveis dummies de setores e dos anos considerados na amostra do estudo.

Com vistas ao alcance dos objetivos propostos, foram realizados o teste de diferenças entre médias, a análise de correlação e a regressão linear múltipla. O primeiro foi utilizado para verificar a existência de diferenças entre os quatro tipos de endividamento nas empresas que adotam as melhores práticas de governança (Nível 1, Nível 2 e Novo Mercado) e nas demais. Dessa forma, o estudo compara dois grupos de empresas: Grupo 1, constituído por empresas que adotam as melhores práticas de governança; e Grupo 2, composto pelas demais empresas. A aplicação da regressão linear múltipla objetivou investigar a relação entre o endividamento e os fatores apontados pela literatura como determinantes da estrutura de capital (governança corporativa, rentabilidade, tamanho e tangibilidade). Para tanto, nos testes estatísticos utilizados no estudo (teste de diferença de média, correlação e regressão) adotou-se os níveis de significância de $10 \%, 5 \%$ e $1 \%$.

\section{Resultados}

A Tabela 1 evidencia a estatística descritiva das características das empresas da amostra, segundo as variáveis adotadas para o estudo, a saber: endividamento de curto prazo, endividamento de longo prazo, endividamento total, endividamento subsidiado, rentabilidade, tamanho e tangibilidade.

Tabela 1

\section{Estatística descritiva dos dados}

\begin{tabular}{ccccccc}
\hline Variável & N & Mínimo & Máximo & Média & $\begin{array}{c}\text { Desvio- } \\
\text { padrão }\end{array}$ & $\begin{array}{c}\text { Coeficiente de } \\
\text { Variação }\end{array}$ \\
\hline ENDCP & 986 & 0,0000 & 0,7072 & 0,0848 & 0,0928 & 2,2598 \\
\hline ENDLP & 986 & 0,0000 & 0,7015 & 0,1639 & 0,1389 & 0,8473 \\
\hline ENDTOT & 986 & 0,0000 & 0,8939 & 0,2487 & 0,1660 & 0,6676 \\
\hline ENDSUB & 120 & 0,0000 & 1,5877 & 0,0666 & 0,1709 & 2,5662 \\
\hline ROA & 986 & $-0,3387$ & 0,8414 & 0,0423 & 0,0980 & 2,3141 \\
\hline TAM & 986 & 8,6618 & 19,4506 & 13,6565 & 1,6826 & 0,1232 \\
\hline TANG & 986 & 0,0000 & 0,9715 & 0,1845 & 0,2223 & 1,2033 \\
\hline
\end{tabular}

Fonte: elaborada pelos autores. 
Como mostra a Tabela 1, as variáveis endividamento de curto prazo (ENDCP), endividamento de longo prazo (ENDLP), endividamento total (ENDTOT) e endividamento subsidiado (ENDSUB) registraram médias $8,5 \%, 16 \%, 25 \%$ e $6,6 \%$, respectivamente. O endividamento subsidiado (ENDSUB) apresenta uma alta dispersão, que pode ser observada pelo coeficiente de variação. O endividamento total (ENDTOT) assinalou a maior média e a maior homogeneidade, ou seja, apresenta um baixo desvio-padrão e um baixo coeficiente de variação. Verifica-se, ainda, na Tabela 1, que a rentabilidade das empresas da amostra assinala média $4,2 \%$, e que a variável apresenta uma alta dispersão.

No intuito de se compreender o comportamento dos tipos de endividamento em relação aos segmentos de listagem da BM\&FBOVESPA, foi feita uma análise estatística descritiva dos dados, conforme mostra a Tabela 2.

Tabela 2

Estatística descritiva dos tipos de endividamento

\begin{tabular}{|c|c|c|c|c|c|}
\hline Variável & Segmento & $\mathbf{N}$ & Média & Desvio-padrão & $\begin{array}{c}\text { Média do desvio do } \\
\text { erro }\end{array}$ \\
\hline \multirow[b]{2}{*}{ ENDCP } & Mercado tradicional & 414 & 0,1013 & 0,1103 & 0,0054 \\
\hline & $\begin{array}{l}\text { Níveis diferenciados de } \\
\text { governança corporativa }\end{array}$ & 572 & 0,0728 & 0,0757 & 0,0032 \\
\hline \multirow[b]{2}{*}{ ENDLP } & Mercado tradicional & 414 & 0,1487 & 0,1411 & 0,0069 \\
\hline & $\begin{array}{l}\text { Níveis diferenciados de } \\
\text { governança corporativa }\end{array}$ & 572 & 0,1749 & 0,1363 & 0,0057 \\
\hline \multirow[b]{2}{*}{ ENDTOT } & Mercado tradicional & 414 & 0,2500 & 0,1806 & 0,0089 \\
\hline & $\begin{array}{l}\text { Níveis diferenciados de } \\
\text { governança corporativa }\end{array}$ & 572 & 0,2478 & 0,1548 & 0,0065 \\
\hline \multirow[b]{2}{*}{ ENDSUB } & Mercado tradicional & 46 & 0,1109 & 0,2617 & 0,0386 \\
\hline & $\begin{array}{l}\text { Níveis diferenciados de } \\
\text { governança corporativa }\end{array}$ & 74 & 0,0390 & 0,0581 & 0,0067 \\
\hline
\end{tabular}

Fonte: elaborada pelos autores.

Com base nos dados da Tabela 2, verifica-se que as empresas não listadas em nenhum segmento diferenciado apresentam maior endividamento médio do que as demais. Nota-se que o endividamento nas empresas participantes dos níveis diferenciados apresenta uma dispersão inferior à das demais empresas. Ressalta-se também que as quantidades de observações dos dois grupos são similares.

Para verificar se há diferenças entre os tipos de endividamento utilizados no estudo (de curto prazo, de longo prazo, total e subsidiado) e os segmentos de listagem da BM\&FBOVESPA, utilizou-se o teste de diferenças entre médias, cujos resultados são mostrados na Tabela 3. Destaca-se que foram realizados testes não paramétricos, pois os pressupostos do teste paramétrico não foram atendidos, ou seja, os dados não seguiram distribuição aproximadamente normal e homogeneidade.

Tabela 3

\section{Resultados dos testes de diferenças entre médias}

\begin{tabular}{ccccc}
\hline Variável & Mann-Whitney U & Wilcoxon W & Z & Asymp. Sig. (2-tailed) \\
\hline ENDCP & $104.062,00$ & $267.940,00$ & $-3,250$ & 0,001 \\
\hline ENDLP & $101.989,50$ & $187.894,50$ & $-3,720$ & 0,000 \\
\hline ENDTOT & $116.260,00$ & $202.165,00$ & 0,486 & 0,627 \\
\hline ENDSUB & $1.147,00$ & $3.922,00$ & $-2,996$ & 0,003 \\
\hline
\end{tabular}

Fonte: elaborada pelos autores. 
Na Tabela 3, constata-se que há diferenças estatísticas entre a média de endividamento nas empresas dos níveis diferenciados de governança corporativa e a das demais. No endividamento de curto prazo (ENDCP), longo prazo (ENDLP) e no subsidiado (ENDSUB), a significância é de 1\%, enquanto no endividamento total (ENDTOT) não houve significância.

No intuito de se investigar a correlação entre as variáveis consideradas no estudo, realizou-se uma análise de correlação, cujos resultados são exibidos na Tabela 4.

Tabela 4

\section{Resultados da análise de correlação}

\begin{tabular}{|c|c|c|c|c|c|c|c|c|}
\hline Variável & 1 & 2 & 3 & 4 & 5 & 6 & 7 & 8 \\
\hline $\operatorname{ENDCP}(1)$ & 1 & & & & & & & \\
\hline ENDLP (2) & $-0,013$ & 1 & & & & & & \\
\hline ENDTOT (3) & $0,548(* * *)$ & $0,829(* * *)$ & 1 & & & & & \\
\hline ENDSUB (4) & $-0,155\left(^{*}\right)$ & $-0,193\left(^{* *}\right)$ & $-0,220\left(^{* *}\right)$ & 1 & & & & \\
\hline GC (5) & $-0,151(* * *)$ & $0,093(* * *)$ & $-0,007$ & $-0,205\left(^{* *}\right)$ & 1 & & & \\
\hline $\mathrm{ROA}(6)$ & $-0,338(* * *)$ & $-0,073(* *)$ & $-0,250(* \star *)$ & $-0,142$ & 0,044 & 1 & & \\
\hline TAM (7) & $-0,254(* \star *)$ & $0,148\left(^{* \star \star}\right)$ & $-0,018$ & $-0,436(* * *)$ & $0,356\left(^{* \star *}\right)$ & $0,128\left(^{* * *}\right)$ & 1 & \\
\hline TANG (8) & 0,046 & 0,151 (***) & $0,152(* * *)$ & $-0,158\left(^{*}\right)$ & $-0,235$ (***) $^{(* *}$ & $-0,009$ & $-0,107(* \star *)$ & 1 \\
\hline
\end{tabular}

Nota: $\left({ }^{*}\right),\left(^{* *}\right)$ e $\left(^{* * *}\right)$ denotam a significância estatística dos coeficientes em $10 \%, 5 \%$ e $1 \%$, respectivamente.

Fonte: elaborada pelos autores.

Com base nas informações evidenciadas na Tabela 4, observa-se que, em linhas gerais, as variáveis independentes não são altamente correlacionadas. Portanto, não se verifica a presença de multicolinearidade entre os regressores do modelo estatístico, atendendo aos modelos propostos a um dos pressupostos da regressão. É possível constatar que o endividamento subsidiado apresenta uma correlação negativa com todas as variáveis independentes.

A Tabela 5 mostra a aplicação dos modelos de regressão utilizados no estudo. Os modelos foram estimados pelo método dos Mínimos Quadrados Ordinários.

Tabela 5

\section{Estimação dos modelos}

\begin{tabular}{|c|c|c|c|c|c|c|c|c|}
\hline Variável & ENDCP & & ENDLP & & ENDTOT & & ENDSUB & \\
\hline \multirow{2}{*}{$\mathrm{GC}$} & $-0,012$ & $(* *)$ & 0,023 & $(* *)$ & 0,011 & & $-0,101$ & $(* *)$ \\
\hline & $(0,006)$ & & $(0,009)$ & & $(0,011)$ & & $(0,048)$ & \\
\hline \multirow{2}{*}{$\mathrm{ROA}$} & $-0,281$ & $(* \star *)$ & $-0,161$ & $(* * *)$ & $-0,442$ & $(* * *)$ & $-0,644$ & $(*)$ \\
\hline & $(0,047)$ & & $(0,043)$ & & $(0,058)$ & & $(0,346)$ & \\
\hline \multirow{2}{*}{ TAM } & $-0,010$ & $(* \star *)$ & 0,010 & $(* * *)$ & $-0,001$ & ‘ & $-0,032$ & $(* *)$ \\
\hline & $(0,002)$ & & $(0,003)$ & & $(0,004)$ & & $(0,014)$ & \\
\hline \multirow{2}{*}{ TANG } & $-0,002$ & & 0,140 & $(\star \star *)$ & 0,138 & $(* \star *)$ & $-0,207$ & $(*)$ \\
\hline & $(0,014)$ & & $(0,028)$ & & $(0,034)$ & & $(0,124)$ & \\
\hline $\mathrm{N}^{\circ}$ de observações & 986 & & 986 & & 986 & & 120 & \\
\hline $\mathrm{F}$ & 8,18 & & 7,99 & & 7,66 & & 1,24 & \\
\hline$p$-value & 0,000 & & 0,000 & & 0,000 & & 0,077 & \\
\hline $\mathrm{R}^{2}$ & 19,95 & & 12,20 & & 12,75 & & 33,87 & \\
\hline
\end{tabular}

Nota: Modelos estimados pelo método dos mínimos quadrados ordinários. Coeficientes estimados e desvios dos erros (entre parênteses) referentes à estimação do modelo da equação.

$\left.\left.{ }^{(*}\right),{ }^{(*}\right)$ e $\left(^{* * *}\right)$ denotam a significância estatística dos coeficientes em $10 \%, 5 \%$ e $1 \%$, respectivamente.

Fonte: elaborada pelos autores. 
Com relação aos aspectos estatísticos dos modelos de regressão, vale informar que todos foram atendidos. A análise de variância forneceu um teste $F$ que permitiu a aceitação da hipótese alternativa, em que a variação da variável dependente é explicada em termos globais pelas variáveis independentes.

Conforme se constatou pela aplicação da análise de regressão, o endividamento subsidiado apresenta características específicas, e em estudos sobre estrutura de capital não é comum uma análise mais descritiva. Segue-se, então, uma análise mais aprofundada sobre esse tipo de endividamento.

No intuito de se identificar o perfil da dívida subsidiada nas empresas da amostra, realizou-se uma análise desse tipo de endividamento. A Tabela 6 apresenta os valores extraídos do website do BNDES (2016).

Tabela 6

Distribuição anual dos valores financiados pelo BNDES às empresas da amostra - 2010-2014

\begin{tabular}{cccc}
\hline Ano & No de Empresas & Valor (R\$) & Proporção (\%) \\
\hline 2010 & 18 & $4.843 .359 .567,00$ & 8,6 \\
\hline 2011 & 21 & $11.484 .160 .035,00$ & 20,5 \\
\hline 2012 & 29 & $17.970 .134 .595,00$ & 32,1 \\
\hline 2013 & 26 & $10.521 .267 .423,00$ & 18,8 \\
\hline 2014 & 26 & $11.238 .941 .202,00$ & 20,0 \\
\hline Total & 120 & $56.057 .862 .822,00$ & 100,0 \\
\hline
\end{tabular}

Fonte: elaborada pelos autores.

Como mostra a Tabela 6, o ano 2012 registrou o maior número de empresas (29) e a maior proporção dos recursos subsidiados (32,1\%). O valor total disponibilizado pelo BNDES para as empresas da amostra no período sob análise (2010-2014) foi superior a R \$ 56 bilhões.

A Tabela 7 evidencia a distribuição dos valores de empréstimos superiores a $R \$ 1.000 .000 .000,00$ concedidos pelo BNDES (2016) às empresas da amostra no período de 2010 a 2014. Na denominação "Outras" estão reunidas 52 empresas.

Tabela 7

Ranking das empresas que receberam empréstimos do BNDES - 2010-2014

\begin{tabular}{ccc}
\hline Empresa & Valor (R\$) & Proporção (\%) \\
\hline Petrobras & $14.418 .240 .366,00$ & 25,7 \\
\hline Klabin & $3.370 .232 .000,00$ & 6,0 \\
\hline Ambev & $3.365 .839 .113,00$ & 6,0 \\
\hline Braskem & $3.253 .928 .979,00$ & 5,8 \\
\hline Sabesp & $3.170 .568 .634,00$ & 5,7 \\
\hline Telefonica & $3.031 .110 .000,00$ & 5,4 \\
\hline B2W Companhia & $1.998 .826 .634,00$ & 3,6 \\
\hline Embraer & $1.943 .092 .605,00$ & 3,5 \\
\hline Oi & $1.804 .975 .760,00$ & 3,2 \\
\hline Fibria Celulose & $1.651 .488 .485,00$ & 2,9 \\
\hline Lojas Americanas & $1.586 .616 .378,00$ & 2,8 \\
\hline CPFL & $1.508 .759 .793,00$ & 2,7 \\
\hline Sanepar & $1.406 .392 .099,00$ & 2,5 \\
\hline Usiminas & $1.086 .363 .000,00$ & 1,9 \\
\hline Outras & $12.461 .428 .976,00$ & 22,2 \\
\hline Total & $56.057 .862 .822,00$ & 100,0 \\
\hline
\end{tabular}

Fonte: elaborada pelos autores. 
De acordo com as informações evidenciadas na Tabela 7, a Petrobras foi a empresa que mais recebeu recursos do BNDES (2016) no período sob análise e somando-se os valores recebidos pela Klabin e Ambev, as três juntas detêm aproximadamente $38 \%$ do total concedido para as empresas da amostra. Destaca-se, também, que 50,5\% (R $\$ 28.307 .186 .091,00)$ do volume total dos recursos subsidiados da amostra estão presentes nas empresas pertencentes ao Mercado Tradicional. Enquanto, 49,5\% (R\$27.750.676.731,00) dos recursos foram destinados a empresas pertencentes aos níveis diferenciados de governança corporativa.

\section{Discussão}

Conforme evidenciado na Tabela 3, pode-se afirmar que, no tocante ao endividamento, as empresas listadas nos segmentos diferenciados apresentam níveis de endividamento inferiores aos das demais empresas. Uma possível explicação para o resultado é que as empresas com as melhores práticas de governança têm uma menor assimetria informacional e com isso estas empresas têm acesso a diferentes fontes de financiamento (Tani \& Albanez, 2016), podendo está utilizando menos a dívida.

De acordo com a Tabela 5, a variável governança corporativa (GC) mostrou significância negativa para o endividamento de curto prazo e o endividamento subsidiado. Por isso, pode-se afirmar que as empresas participantes dos níveis diferenciados de governança corporativa tendem a apresentar menos endividamento subsidiado, ou seja, esse fato não influencia a decisão do BNDES de conceder financiamentos. Enquanto isso, a participação nos níveis diferenciados de governança corporativa influencia positivamente a captação de dívida de longo prazo, o que pode ser explicado pelo fato de as empresas desse grupo tenderem a preferir empréstimos com prazos maiores ao invés de curto prazo.

No que tange ao endividamento total, nota-se que a governança não influencia uma melhor captação de recursos externos, confirmando o estudo de Vieira et al. (2011), que também não identificou relação entre estrutura de capital e governança corporativa.

Diante do exposto até aqui, vale mencionar que os resultados encontrados na presente pesquisa confirmam em parte outros estudos nacionais, que já encontraram tanto uma relação positiva como uma relação negativa entre estrutura de capital e governança corporativa (Cicogna, Toneto Junior \& Valle, 2007; Fonseca et al., 2016; Silveira et al., 2008).

Ainda na Tabela 5, percebe-se que a rentabilidade (ROA) tem um efeito negativo sobre o endividamento, ou seja, a empresa brasileira segue o comportamento-base da teoria Pecking Order. Por isso, pode-se afirmar que as empresas priorizam o uso de recursos gerados internamente para financiar seus projetos. Esse efeito ocorre relativamente a todos os quatro tipos de endividamento citados no estudo. A variável rentabilidade apresentou resultados convergentes entre o presente estudo e várias pesquisas nacionais e estrangeiras em diversos períodos (Bastos et al., 2009; Bevan \& Danbolt, 2002; Booth, Aivazian, Demirguc-Kunt \& Maksimovic, 2001; Chen, 2004; Correa et al., 2013; Haron, 2014; Rajan \& Zingales, 1995; Titman \& Wessels, 1988).

A Tabela 5 destaca ainda que o tamanho gera efeitos diferentes no endividamento de curto prazo (ENDCP) e no endividamento subsidiado (ENDSUB), e que esse efeito é negativo. Portanto, quanto maior for o tamanho, menos a empresa apresenta esses tipos de endividamento. Enquanto isso, o endividamento de longo prazo (ENDLP) apresentou uma relação positiva, que pode ser explicada pela imagem e reputação da empresa no mercado (Crisóstomo \& Pinheiro, 2015) ou pelas garantias que ela pode obter junto às instituições de crédito. Destaca-se, com esse resultado, a inversão da influência do tamanho sobre o endividamento, que tem efeito negativo no endividamento de curto prazo ao oposto do efeito positivo verificado no endividamento de longo prazo. O resultado pode ser um indicativo da menor necessidade de grandes empresas por financiamentos de curto prazo. 
Observa-se que a tangibilidade (TANG) apresentou uma relação positiva com o endividamento de longo prazo e o endividamento total, confirmando as teorias financeiras; ou seja, quanto mais bens tangíveis a empresa possui, mais garantias ela pode disponibilizar junto às instituições de crédito. A tangibilidade (TANG) é uma variável bastante utilizada em estudos empíricos, e a relação positiva é quase sempre confirmada (Albanez \& Valle, 2009; Chen, 2004).

Pela magnitude dos valores apresentados na Tabela 6, percebe-se a relevância dos bancos de desenvolvimento no país, ratificada por Póvoa et al. (2015), segundo os quais os bancos de desenvolvimento têm grande importância na concessão de crédito no Brasil, e o BNDES é o mais atuante deles.

Ressalta-se que, entre as 66 empresas consideradas para o valor total da Tabela 7, 11 pertencem ao setor elétrico, evidenciando a importância desse tipo de financiamento para o segmento, que necessita de elevados investimentos.

\section{Considerações Finais}

A presente pesquisa teve por principal objetivo analisar a relação entre estrutura de capital e governança corporativa. Para tanto, foram analisadas as empresas não financeiras listadas na BM\&FBOVESPA, levando-se em conta os exercícios do período de 2010 a 2014.

Os resultados apontam que, em linhas gerais, o endividamento nas empresas é baixo, o que requer uma melhor utilização dos recursos recebidos, principalmente em projetos que garantam um retorno adequado. A inadequada utilização dos recursos pode provocar sérios problemas, como, por exemplo, a falência. Nesse contexto, destacam-se os recursos subsidiados, que apresentam algumas vantagens, como taxas de juros bem abaixo da média praticada no mercado, longo período de carência para reembolso de empréstimos e financiamento parcelado em longo prazo.

$\mathrm{Na}$ comparação entre a estrutura de capital nas empresas que adotam as melhores práticas de governança e a das demais empresas, constatou-se uma significativa diferença estatística. As empresas não participantes dos níveis diferenciados de governança corporativa apresentam endividamentos mais altos, quando comparadas com as demais. Dentre as possíveis explicações para esse resultado, destacam-se as seguintes: (i) as instituições financeiras podem estar se preocupando mais com os projetos de investimento e/ou características da empresa, como fluxo de caixa, rentabilidade, bens que podem ser oferecidos em garantia, reputação perante a sociedade, e menos com o fato de a empresa adotar ou deixar de adotar as melhores práticas de governança corporativa, aqui representado pela participação em segmento de listagem da BM\&FBovespa; e (ii) as empresas dos níveis diferenciados podem vir se comportando de acordo com o que preceitua a teoria Pecking Order, e, por isso, utilizam os recursos gerados internamente, necessitando menos dos recursos financeiros externos para seus investimentos.

Os resultados da análise de regressão demonstram que a governança corporativa influencia negativamente o endividamento subsidiado, ou seja, a participação da empresa em um dos níveis diferenciados de governança corporativa da BM\&FBOVESPA impacta de forma negativa a obtenção desse tipo de endividamento. Observou-se, também, que a rentabilidade apresentou uma relação negativa nos quatro tipos de endividamento (de curto prazo, de longo prazo, total e subsidiado), confirmando que as empresas praticam o que propõe a Teoria Pecking Order.

Acredita-se que a presente pesquisa contribui para enriquecer a bibliografia sobre estrutura de capital ao incorporar a dívida subsidiada como uma das variáveis explicativas do modelo, além de a variável governança corporativa ter sido analisada nos quatro tipos de endividamento. Devido à sua grande importância para o meio empresarial e ao fato de os resultados dos estudos acadêmicos serem, em linhas gerais, heterogêneos, as discussões sobre estrutura de capital contribuem de alguma forma para o avanço nesse campo de pesquisa. 
O estudo apresenta algumas limitações como, por exemplo, a adoção dos níveis diferenciados como proxy para a governança corporativa. Além disso, destaca-se que para o endividamento subsidiado foi utilizado. Apenas a variável financiamento junto ao BNDES. Como sugestão para estudos futuros, indica-se a construção de um índice de governança corporativa que contemple características específicas para uma melhor mensuração da governança nas empresas. Além disso, recomenda-se a utilização de um período mais longo de análise e a ampliação da amostra, considerando-se empresas de outras economias emergentes similares à do Brasil. Destarte, sugere-se a utilização de outras variáveis que possam explicar o endividamento nas empresas e uma análise de outras dívidas subsidiadas contraídas em outros bancos de desenvolvimento.

\section{Referências}

Albanez, T. \& Valle, M. R. (2009). Impactos da assimetria de informação na estrutura de capital de empresas brasileiras abertas. Revista Contabilidade \& Finanças, 20(51), pp. 6-27. DOI: https://doi. org/10.1590/S1519-70772009000300002

Armstrong, C. S., Guay, W. R. \& Weber, J. P. (2010). The role of information and financial reporting in corporate governance and debt contracting. Journal of Accounting and Economics, 50(2-3), pp. 179234. DOI: https://doi.org/10.1016/j.jacceco.2010.10.001

Arruda, M. P., Girão, L. F. A. P. \& Lucena, W. G. L. (2015). Assimetria informacional e o preço das ações: análise da utilização das redes sociais nos mercados de capitais brasileiro e norte-americano. Revista Contabilidade \& Finanças, 26(69), pp. 317-330. DOI: https://doi.org/10.1590/1808-057x201501540

Assaf Neto, A. \& Lima, F. G. (2010). Fundamentos de administração financeira. São Paulo: Atlas.

Bachiller, J. V. (2016). Das privatizações à nova estratégia de desenvolvimento - a trajetória do BNDES entre 1990 e 2010. Desenvolvimento em Questão, 14(36), pp. 5-30. DOI: https://doi.org/10.21527/22376453.2016.36.5-30

Baker, M. \& Wurgler, J. (2002). Market timing and capital structure. The Journal of Finance, 57(1), pp. 1-32. DOI: https://doi.org/10.1111/1540-6261.00414

Barros, C. M. E., Silva, P. Y. C. \& Voese, S. B. (2015). Relação entre o custo da dívida de financiamentos e governança corporativa no Brasil. Contabilidade, Gestão e Governança, 18(2), pp. 7-26.

Bastos, D. D., Nakamura, W. T. \& Basso, L. F. C. (2009). Determinantes da estrutura de capital das companhias abertas na América Latina: um estudo empírico considerando fatores macroeconômicos e institucionais. Revista de Administração Mackenzie, 10(6), 47-77. DOI: https://doi.org/10.1590/ S1678-69712009000600005

Bevan, A. A. \& Danbolt, J. (2002). Capital structure and its determinants in the UK - a decompositional analysis. Applied Financial Economics, 12(3), pp. 159-170. DOI: https://doi. org/10.1080/09603100110090073

Banco Nacional de Desenvolvimento Econômico e Social. (2016). Central de downloads. Recuperado em 10 novembro, 2016, de http://www.bndes.gov.br/wps/portal/site/home/transparencia/centraldedownloads

Booth, L., Aivazian, V., Demirguc-Kunt, A. \& Maksimovic, V. (2001). Capital structures in developing countries. The Journal of Finance, 56(1), pp. 87-130. DOI: https://doi.org/10.1111/0022-1082.00320

Brito, G. A. S., Corrar, L. J. \& Batistella, F. D. (2007). Fatores determinantes da estrutura de capital das maiores empresas que atuam no Brasil. Revista Contabilidade \& Finanças 18(43), pp. 9-19. DOI: https://doi.org/10.1590/S1519-70772007000100002 
Campos, A. L. S. \& Nakamura, W. T. (2013). Folga financeira avaliada como endividamento relativo e estrutura de capital. Revista de Finanças Aplicadas, 1(1), pp. 1-19.

Chang, Y.-K., Chen, Y.-L., Chou, R. K. \& Huang, T.-H. (2015). Corporate governance, product market competition and dynamic capital structure. International Review of Economics and Finance, 38(1), pp. 44-55. DOI: https://doi.org/10.1016/j.iref.2014.12.013

Chang, Y.-K., Chou, R. K. \& Huang, T.-H. (2014). Corporate governance and the dynamics of capital structure: New evidence. Journal of Banking \& Finance, 48(1), pp. 374-385. DOI: https://doi. org/10.1016/j.jbankfin.2014.04.026

Chen, D.-H., Chen, C.-D., Chen, J. \& Huang, Y.-F. (2013). Panel data analyses of the pecking order theory and the market timing theory of capital structure in Taiwan. International Review of Economics and Finance, 27(1), pp. 1-13. DOI: https://doi.org/10.1016/j.iref.2012.09.011

Chen, J. J. (2004). Determinants of capital structure of Chinese-listed companies. Journal of Business Research, 57(1), pp. 1341-1351. DOI: https://doi.org/10.1016/S0148-2963(03)00070-5

Chen, W.-P., Chung, H., Hsu, T.-L. \& Wu, S. (2010). External financing needs, corporate governance, and firm value. Corporate Governance: An International Review, 18(3), pp. 234-249. DOI: https://doi. org/10.1111/j.1467-8683.2010.00801.x

Cicogna, M. P. V., Toneto Junior, R. \& Valle, M. R. (2007). O impacto da adesão a padrões mais elevados de governança sobre o financiamento empresarial. Revista de Administração da USP, 42(1), pp. 52-63.

Cooper, D. R. \& Schindler, P. S. (2011). Métodos de pesquisa em administração (10ª ed.). Porto Alegre: Bookman.

Correa, C. A., Basso, L. F. C. \& Nakamura, W. T. (2013). A estrutura de capital das maiores empresas brasileiras: análise empírica das teorias de pecking order e trade-off usando panel data. Revista de Administração Mackenzie, 14(4), pp. 106-133. DOI: https://doi.org/10.1590/S1678-69712013000400005

Crisóstomo, V. L. \& López-Iturriaga, F. (2011). Financiamiento de la inversión y las imperfecciones del mercado. Información Financiera, Gerencia y Control, 1(3), pp.11-48.

Crisóstomo, V. L. \& Pinheiro, B. G. (2015). Estrutura de capital e concentração de propriedade da empresa brasileira. Revista de Finanças Aplicadas, 4(1), pp. 1-30.

Dalmácio, F. Z., Lopes, A. B., Rezende, A. J. \& Sarlo Neto, A. (2013). Uma análise da relação entre governança corporativa e acurácia das previsões dos analistas do mercado brasileiro. Revista de Administração Mackenzie, 14(5), pp. 104-139. DOI: https://doi.org/10.1590/S1678-69712013000500005

David, M., Nakamura, W. T. \& Bastos, D. D. (2009). Estudo dos modelos trade-off e pecking order para as variáveis endividamento e payout em empresas brasileiras (2000 - 2006). Revista de Administração Mackenzie, 10(6), pp. 132-153. DOI: https://doi.org/10.1590/S1678-69712009000600008

De Luca, M. M. M., Maia, A. B. G. R., Cardoso, V. I. C., Vasconcelos, A. C. \& Cunha, J. V. A. (2014). Intangible assets and superior and sustained performance of innovative Brazilian firms. BAR Brazilian Administration Review, 11(4), pp. 407-440. DOI: https://doi.org/10.1590/1807-7692bar2014130012

Detthamrong, U., Chancharat, N. \& Vithessonthi, C. (2017). Corporate governance, capital structure and firm performance: evidence from Thailand. Research in International Business and Finance, 42(1), pp. 689-709. DOI: https://doi.org/10.1016/j.ribaf.2017.07.011

Fonseca, C. V. C., Silveira, R. L. F. \& Hiratuka, C. (2016). A relação entre a governança corporativa e a estrutura de capital das empresas brasileiras no período 2000-2013. Enfoque: Reflexão Contábil, 35(2), pp. 35-52. DOI: https://doi.org/10.4025/enfoque.v35i2.29673

Gray, D. E. (2012). Pesquisa no mundo real (2a ed.). Porto Alegre: Penso. 
Handoo, A. \& Sharma, K. (2014). A study on determinants of capital structure in India. IIMB Management Review, 26(1), pp. 170-182. DOI: https://doi.org/10.1016/j.iimb.2014.07.009

Haron, R. (2014). Capital structure inconclusiveness: evidence from Malaysia, Thailand and Singapore. International Journal of Managerial Finance, 10(1), pp. 23-38. DOI: https://doi.org/10.1108/IJMF03-2012-0025

Jensen, M. C. (1986). Agency costs of free cash flow, corporate finance, and takeovers. The American Economic Review, 76(2), pp. 323-329.

Jensen, M. C. \& Meckling, W. H. (1976). Theory of the firm: managerial behavior, agency cost and ownership structure. Journal of Financial Economics, 3(4), pp. 305-360. DOI: https://doi.org/10.1016/0304$-405 \mathrm{X}(76) 90026-\mathrm{X}$

Jiraporn, P., Kim, J. C., Kim, Y. S. \& Kitsabunnarat, P. (2012). Capital structure and corporate governance quality: evidence from the Institutional Shareholder Services (ISS). International Review of Economics and Finance, 22(1), pp. 208-221. DOI: https://doi.org/10.1016/j.iref.2011.10.014

Jõeveer, K. (2013). Firm, country and macroeconomic determinants of capital structure: evidence from transition economies. Journal of Comparative Economics, 41(1), 294-308. DOI: https://doi. org/10.1016/j.jce.2012.05.001

Liao, L. K., Mukherjee, T. \& Wang, W. (2015). Corporate governance and capital structure dynamics: an empirical study. The Journal of Financial Research, 38(2), pp. 169-191. DOI: https://doi.org/10.1111/ jfir. 12057

Machado, L. K. C., Prado, J. W., Vieira, K. C., Antonialli, L. M. \& Santos, A. C. (2015). A relevância da estrutura de capital no desempenho das firmas: uma análise multivariada das empresas brasileiras de capital aberto. Revista de Educação e Pesquisa em Contabilidade, 9(4), pp. 397-414. DOI: https:// doi.org/10.17524/repec.v9i4.1313

Martins, G. A. \& Theóphilo, C. R. (2009). Metodologia da investigação científica para ciências sociais aplicadas (2a ed.). São Paulo: Atlas.

Modigliani, F. \& Miller, M. H. (1958). The cost of capital, corporation finance and theory of investment. The American Economic Review, 48(3), pp. 261-297.

Myers, S. C. (1984). The capital structure puzzle. The Journal of Finance, 39(3), pp. 575-592. DOI: https:// doi.org/10.2307/2327916

Myers, S. C. \& Majluf, N. S. (1984). Corporate financing and investment decisions when firms have information that investors do not have. Journal of Financial Economics, 13(2), pp. 187-221. DOI: https:// doi.org/10.1016/0304-405X(84)90023-0

Pohlmann, M. C. \& Iudícibus, S. D. (2010). Relação entre a tributação do lucro e a estrutura de capital das grandes empresas no Brasil. Revista Contabilidade \& Finanças, 21(53), pp. 1-25. DOI: https://doi. org/10.1590/S1519-70772010000200002

Póvoa, A. C. S. \& Nakamura, W. T. (2015). Relevância da estrutura de dívida para os determinantes da estrutura de capital: um estudo com dados em painel. Revista Contemporânea de Contabilidade, 12(25), pp. 3-26. DOI: https://doi.org/10.5007/2175-8069.2015v12n25p03

Póvoa, A. C. S., Vieira, W. S., Kudlawicz, C. \& Bach, T. M. (2015). A governança corporativa como fator determinante para a estrutura da dívida: o caso brasileiro. Anais do Encontro da Associação Nacional dos Programas de Pós-Graduação em Administração - EnANPAD, Belo Horizonte, BH, Brasil, 39.

Rajan, R. G., \& Zingales, L. (1995). What do we know about capital structure? Some evidence from international data. The Journal of Finance, 50(5), pp. 1421-1460. DOI: https://doi.org/10.1111/j.1540-6261.1995. tb05184.x 
Silveira, A. D. M., Perobelli, F. F. C., \& Barros, L. A. B. C. (2008). Governança corporativa e os determinantes da estrutura de capital: evidências empíricas no Brasil. Revista de Administração Contemporânea, 12(3), pp. 763-788. DOI: https://doi.org/10.1590/S1415-65552008000300008

Sun, J., Ding, L., Guo, J. M. \& Li, Y. (2016). Ownership, capital structure and financing decision: evidence from the UK. The British Accounting Review, 48(4), pp. 448-463. DOI: https://doi.org/10.1016/j. bar.2015.04.001

Tani, B. B. \& Albanez, T. (2016). Decisões de financiamento das companhias listadas nos diferentes segmentos de governança da BM\&FBovespa segundo a teoria de pecking order. Contabilidade, Gestão e Governança, 19(2), pp. 317-334. DOI: https://doi.org/10.21714/19843925_2016v19n2a8

Terra, P. R. S. (2009). A are leverage and debt maturity complements or substitutes? Evidence from Latin America. Revista de Administração Mackenzie, 10(6), pp. 4-24. DOI: https://doi.org/10.1590/ S1678-69712009000600003

Thippayana, P. (2014). Determinants of capital structure in Thailand. Procedia - Social and Behavioral Sciences, 143(1), pp. 1074-1077. DOI: https://doi.org/10.1016/j.sbspro.2014.07.558

Titman, S. \& Wessels, R. (1988). The determinants of capital structure choice. The Journal of Finance, 43(1), pp. 1-19. DOI: https://doi.org/10.1111/j.1540-6261.1988.tb02585.x

Vieira, K. M., Velasquez, M. D. P., Losekann, V. L., \& Ceretta, P. S. (2011). A influência da governança corporativa no desempenho e na estrutura de capital das empresas listadas na Bovespa. Revista Universo Contábil, 7(1), pp. 49-67. DOI: https://doi.org/10.4270/ruc.2011104

Yang, B. (2013). Dynamic capital structure with heterogeneous beliefs and market timing. Journal of Corporate Finance, 22(1), pp. 254-277. DOI: https://doi.org/10.1016/j.jcorpfin.2013.05.003 